\title{
A case of lethal spontaneous massive hemothorax in a patient with neurofibromatosis 1
}

\author{
Luisa Zacarias Föhrding ${ }^{1}$, Timur Sellmann², Sebastian Angenendt', Detlef Kindgen-Milles², Stefan A Topp', \\ Bernhard Korbmacher ${ }^{3}$, Artur Lichtenberg ${ }^{3}$ and Wolfram T Knoefel ${ }^{1 *}$
}

\begin{abstract}
Neurofibromatosis type 1 is an autosomal dominant disease characterized by multiple dermatological disorders amongst others. Among the less frequent manifestations are vascular abnormalities. Here, we present a case of spontaneous massive hemothorax in a 39-year-old Caucasian woman with neurofibromatosis 1 and a thoracic meningocele with a lethal outcome despite extensive surgical intervention as well as intensive care measures. Spontaneous hemothorax is a rare, but potentially lethal complication of neurofibromatosis type 1, which necessitates quick and decisive intervention; endovascular embolization where possible, otherwise aggressive surgical intervention in unstable patients.
\end{abstract}

Keywords: Neurofibromatosis type 1, Spontaneous hemothorax, Meningocele, Endovascular embolization

\section{Background}

Neurofibromatosis 1 (NF1) is an autosomal dominant disease characterized by café-au-lait macules, neurofibromas of any type, axillary and inguinal freckling and Lisch nodules in the iris. Additionally, numerous vascular manifestations have been reported [1-3]. Intrathoracic meningoceles have also been described in NF1 several times [4-6]. Spontaneous hemothorax is a rare but potentially lethal complication [7-9]. Here, we present a case of a lethal spontaneous hemothorax associated to an intrathoracic meningocele in a patient with NF 1.

\section{Case presentation}

A 39-year old Caucasian female with known NF1 presented herself in the emergency department of an outside hospital with acute symptoms of thoracic pain and dyspnea. Her history was otherwise significant for an extensive thoracic myelomeningocele and status post-surgical correction of a thoracic scoliosis using a tibia bone graft 27 years earlier.

On physical examination at the outside hospital, she was awake, afebrile, blood pressure of $80 / 40 \mathrm{mmHg}$ and a heart

\footnotetext{
* Correspondence: WolframTrudo.Knoefel@med.uni-duesseldorf.de ${ }^{1}$ Department of General, Visceral and Paediatric Surgery, Heinrich Heine University Düsseldorf, Düsseldorf, Germany

Full list of author information is available at the end of the article
}

rate of 100 beats per minute. The initial haemoglobin was $12.5 \mathrm{~g} / \mathrm{dl}$, quickly deteriorating to $8.4 \mathrm{~g} / \mathrm{dl}$ in the following hour. Chest x-ray (Figure 1) was performed 40 mins after admission and revealed an extensive mediastinal shift. Subsequent computer tomography (Figure 2) was performed $1 \mathrm{~h}$ later at the outside hospital and revealed a massive hemothorax on the left side. The patient was intubated orotracheally because of hemorrhagic shock and imminent cardiopulmonary arrest and received seven packed red blood cell concentrates. A thoracic drainage was inserted prior to transfer. $4 \mathrm{~h} 10 \mathrm{~min}$ after admission to the outside hospital the patient was transferred to our institution and arrived there $1 \mathrm{~h}$ later.

On admission, she was highly catecholamine-dependent. We found one left-thoracic suction drainage installed using Monaldi technique with $50 \mathrm{ml}$ of blood in the drainage bottle. During placement of venous and arterial lines she suffered a cardiocirculatory arrest. Resuscitation was immediately initiated and we proceeded with performing an emergency exploratory left antero-lateral thoracotomy in the intensive care unit. Thereupon 2 liters of blood exsanguinated spontaneously. Despite massive blood transfusions (16 packed red blood cells, 2 thrombocyte concentrates, and 4 fresh frozen plasmas) and intravenous fluid administration no sufficient circulation could be established. Due to massive bleeding and very difficult operative conditions it was not possible to perform 


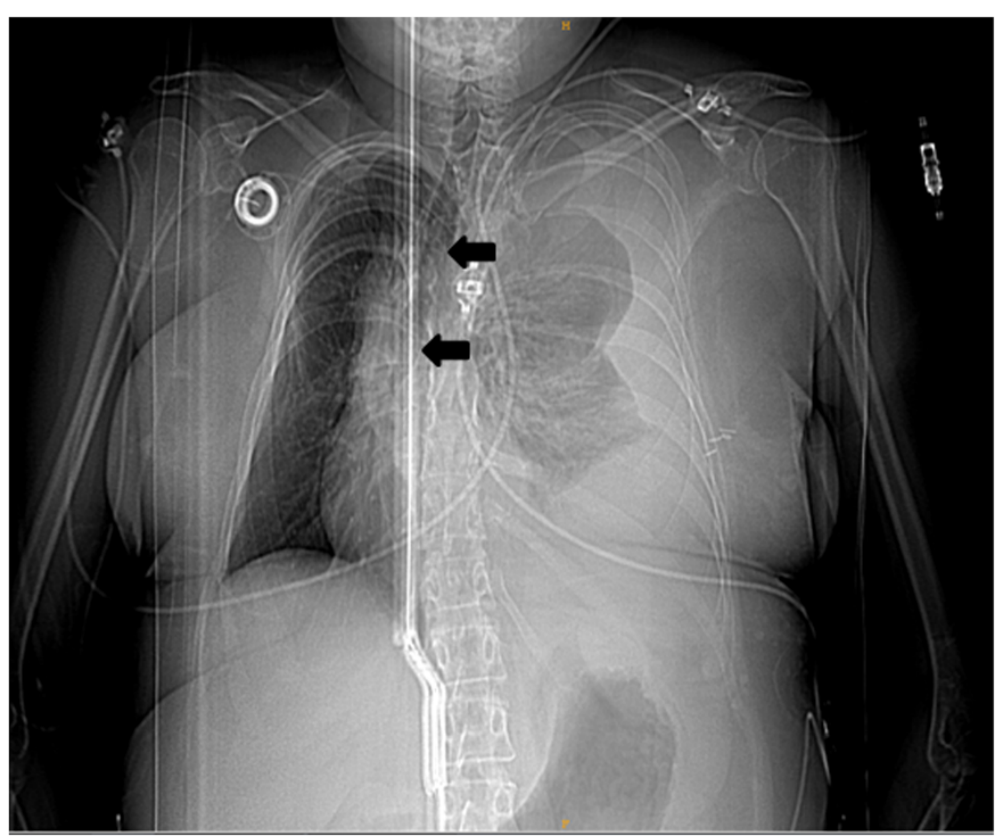

Figure 1 Chest radiography showing extensive opacity in the left hemithorax. Note the massive mediastinal shift (arrows).

either an exploration of the thorax or an open cardiac massage via the same approach, which forced us to take a second approach through a median sternotomy for cardiac massage. Upon exploration of the thoracic cavity through the antero-lateral approach a large tumor, dorsal on the left side next to the vertebral column with massive bleeding, was detected. Despite several sutures and massive transfusions the bleeding could not be stopped and no sufficient blood pressure could be established. 7 h 30 mins after her first admission to the outside hospital and three hours after arriving at our institution the patient succumbed to the bleeding.

On autopsy multiple neurofibromas and several caféau-lait spots were scattered over the entire body surface. In the area of the tibia bone graft in the upper thoracic spine a protrusion of the dura mater of $8 \times 10 \mathrm{~cm}$ was found. This meningocele showed a $1.8 \mathrm{~cm}$ perforation, which was probably due to the surgical procedures. Unfortunately, the autopsy could not reveal a distinct source of bleeding, but with a high probability, given the proximity to the oozing point, the bleeding must have originated from an intercostal artery.

\section{Conclusions}

We hereby report a case of spontaneous hemothorax in a patient with neurofibromatosis 1 who went into cardiac arrest due to massive bleeding and finally died from uncontrollable hemorrhage. Despite immediate surgical intervention we were unable to locate the precise oozing point of the arterial bleeding due to the proximity to a large meningocele and the patient could not be resuscitated successfully.

So far, thoracic meningoceles have not been directly implicated in bleedings associated to NF1. The pathogenic relevance of the meningocele as the source of the bleeding, however, could not be supported by CT and autopsy. A deformity of the thorax and a mechanical stretching of an intercostal artery could have played a role [4]. However, the proximity of the oozing point to the large intrathoracic meningocele considerably complicated the operative procedure.

Since the case had an unfavorable outcome, one has to investigate whether the management was optimal. In NF1 surgical repair of bleeding vessels is complicated by arterial fragility due to intimal and medial dysplasia [10]. For this reason, endovascular embolization of arterial aneurysms is generally considered to be the treatment of choice in a stable hemodynamic situation as it is less invasive and more effective than surgical intervention $[1,9,11,12]$. Video-assisted thoracoscopy (VATS) may be an alternative for evacuating a hematoma, especially after controlling the bleeding, e.g. by endovascular measures. During initial management with acute or even uncontrolled bleeding VATS seems to be suitable only in exceptional cases [13].

Since the patient in this case went directly into hemorrhagic shock and an unsatisfactory stabilization of the hemodynamic situation did not allow for an angiography, we considered an immediate thoracotomy 

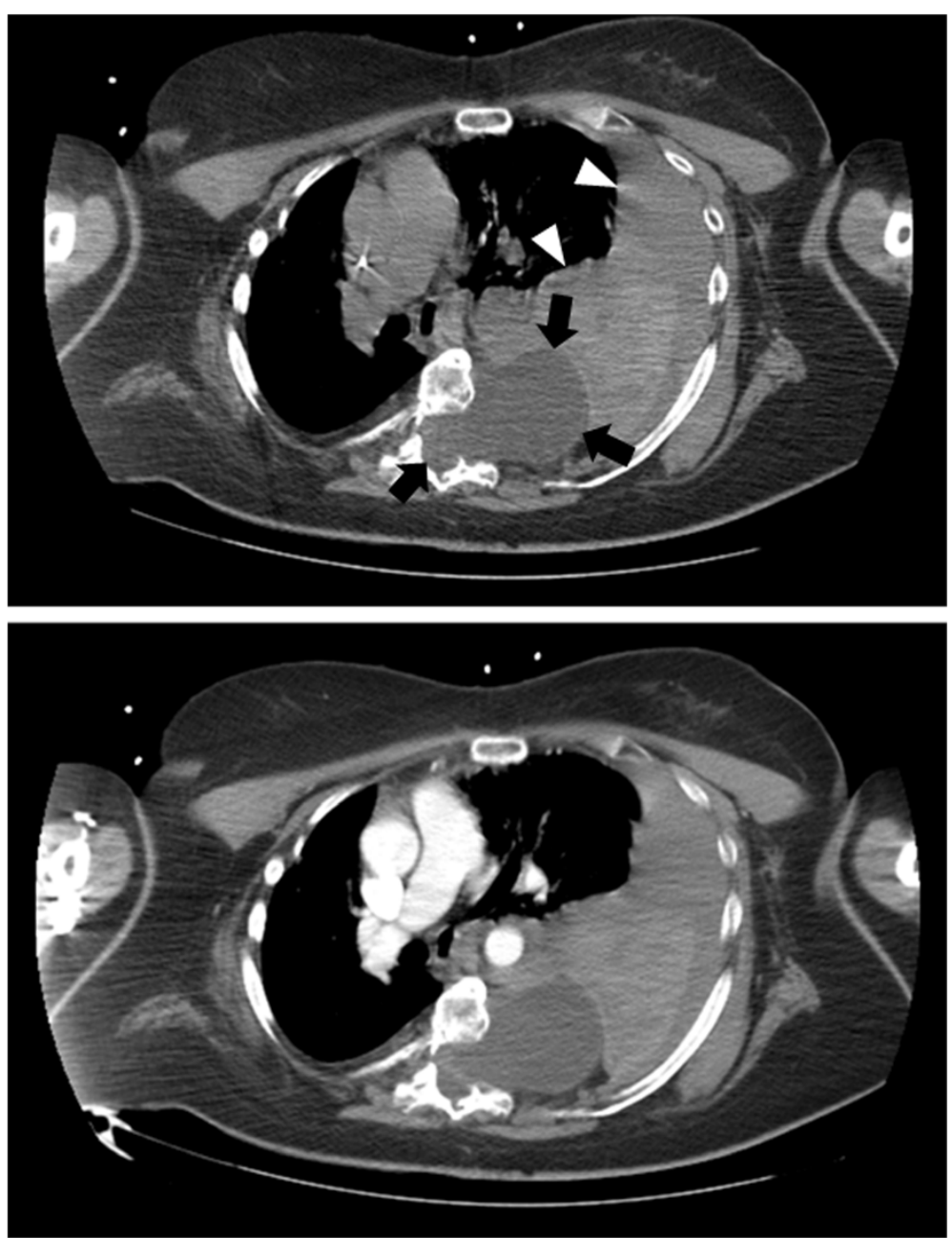

Figure 2 Chest computer tomography (CT). Upper figure: without contrast enhancement. Lower figure: with contrast enhancement. The arrows show the intrathoracic meningocele and the arrowheads show the hemothorax.

as the only viable alternative. In line with this view, Miura et al. consider an emergent and aggressive surgical treatment to be indicated in patients in a hemodynamically unstable condition [14].

Collectively, it is conceivable that a faster transportation to our institution after a correct diagnosis of NF1associated hemothorax and a timely embolization before the patient went into shock may have led to a favorable outcome. We therefore conclude that a quick diagnosis which facilitates early preparation of endovascular treatment is crucial in the management of spontaneous hemothorax in patients with NF1.

\section{Consent}

Written informed consent was obtained from the patient's next of kin for publication of this case report and any accompanying images. A copy of the written consent is available for review by the Editor-in-Chief of this journal.

\section{Abbreviations}

CT: Computer tomography; NF1: Neurofibromatosis 1.

\section{Competing interests}

The authors declare that they have no competing interests.

\section{Authors' contributions}

LZF, TS, BK, DK-M designed the research; LZF, TS and SAT collected the data; LZF drafted the manuscript; WTK, AL and TS helped to draft the manuscript. All authors revised the manuscript. All authors read and approved the final manuscript.

\section{Acknowledgements}

We thank Dr. Jörg Stammkötter for helping in obtaining the patient's medical history.

\section{Author details}

'Department of General, Visceral and Paediatric Surgery, Heinrich Heine University Düsseldorf, Düsseldorf, Germany. ${ }^{2}$ Department of Anesthesiology, Heinrich Heine University Düsseldorf, Düsseldorf, Germany. ${ }^{3}$ Department of Cardiovascular Surgery, Heinrich Heine University Düsseldorf, Düsseldorf, Germany.

Received: 4 May 2014 Accepted: 8 October 2014

Published online: 29 October 2014 


\section{References}

1. Kipfer B, Lardinois D, Triller J, Carrel T: Embolization of a ruptured intercostal artery aneurysm in type I neurofibromatosis. Eur J Cardiothorac Surg 2001, 19:721-723.

2. Oderich GS, Sullivan TM, Bower TC, Gloviczki P, Miller DV, Babovic-Vuksanovic D, Macedo TA, Stanson A: Vascular abnormalities in patients with neurofibromatosis syndrome type I: clinical spectrum, management, and results. J Vasc Surg 2007, 46:475-484.

3. Salyer WR, Salyer DC: The vascular lesions of neurofibromatosis. Angiology 1974, 25:510-519.

4. Kaneda H, Saito T, Konobu T, Saito Y: Chest wall bleeding with giant intrathoracic meningocele in neurofibromatosis type 1. Interact Cardiovasc Thorac Surg 2011, 12:328-330.

5. Miles J, Pennybacker J, Sheldon P: Intrathoracic meningocele. Its development and association with neurofibromatosis. J Neurol Neurosurg Psychiatr 1969, 32:99-110.

6. Rainov NG, Heidecke $V$, Burkert W: Thoracic and lumbar meningocele in neurofibromatosis type 1. Report of two cases and review of the literature. Neurosurg Rev 1995, 18:127-134.

7. Nopajaroonsri C, Lurie AA: Venous aneurysm, arterial dysplasia, and near-fatal hemorrhages in neurofibromatosis type 1. Hum Pathol 1996, 27:982-985.

8. Pezzetta E, Paroz A, Ris HB, Martinet O: Spontaneous hemothorax associated with von Recklinghausen's disease. Eur J Cardiothorac Surg 2003, 23:1062-1064.

9. Teitelbaum GP, Hurvitz RJ, Esrig BC: Hemothorax in type I neurofibromatosis. Ann Thorac Surg 1998, 66:569-571.

10. Greene JF, Fitzwater JE, Burgess J: Arterial lesions associated with neurofibromatosis. Am J Clin Pathol 1974, 62:481-487.

11. Arai K, Sanada J, Kurozumi A, Watanabe T, Matsui O: Spontaneous hemothorax in neurofibromatosis treated with percutaneous embolization. Cardiovasc Intervent Radiol 2007, 30:477-479.

12. Sandhu C, Sabharwal T: Spontaneous hemothorax in patients with neurofibromatosis treated with percutaneous embolization. Cardiovasc Intervent Radiol 2008, 31:1260-1261.

13. Mydin Muhammad Izanee M, Sharma A, Zia Z, Hawari M, Jadoon M, Majewski A: A novel approach in managing right-sided haemothorax in neurofibromatosis type 1. Asian Cardiovasc Thorac Ann 2014, doi:10.1177/0218492314522636.

14. Miura T, Kawano Y, Chujo M, Miyawaki M, Mori H, Kawahara K: Spontaneous hemothorax in patients with von Recklinghausen's disease. Jpn J Thorac Cardiovasc Surg 2005, 53:649-652.

doi:10.1186/s13019-014-0172-y

Cite this article as: Zacarias Föhrding et al:: A case of lethal spontaneous massive hemothorax in a patient with neurofibromatosis 1. Journal of Cardiothoracic Surgery 2014 19:172.

\section{Submit your next manuscript to BioMed Central and take full advantage of:}

- Convenient online submission

- Thorough peer review

- No space constraints or color figure charges

- Immediate publication on acceptance

- Inclusion in PubMed, CAS, Scopus and Google Scholar

- Research which is freely available for redistribution 